\title{
SOLVING AN EPQ MODEL WITH REWORK AND SERVICE LEVEL CONSTRAINT
}

\author{
Yuan-Shyi Peter Chiu ${ }^{1}$, Singa Wang Chiu ${ }^{2, *}$, and Hong-Dar Lin ${ }^{3}$ \\ ${ }^{1,3}$ Department of Industrial Engineering and Management, Chaoyang University of \\ Technology, Taichung, Taiwan \\ ${ }^{2}$ Department of Business Administration, Chaoyang University of Technology, Taichung \\ 413, Taiwan. "Corresponding author: E-mail: swang@,mail.cyut.edu.tw
}

\begin{abstract}
This paper examines an economic production quantity (EPQ) model with rework and service level constraint. First, we prove that the expected overall costs for an imperfect EPQ model with backlogging permitted is less than or equal to that of the one without backlogging. Secondly, the relationship between "imputed backorder cost" and maximal shortage level is derived for decision-making on whether the required service level is achievable. Then an equation for calculating the intangible backorder cost is proposed for situation when the required service level is not attainable. By including this intangible backorder cost in mathematical analysis, one can derive a new optimal lot-size policy that minimizes expected total costs as well as satisfies the maximal shortage level constraint for the EPQ model with rework. Numerical example is provided to demonstrate its practical usage.
\end{abstract}

Keywords- Manufacturing, Economic production quantity, Service level constraint, Reworking

\section{INTRODUCTION}

In manufacturing sector, when items are produced internally instead of being obtained from an outside supplier, the EPQ model is often employed to determine the optimal production lot-size that minimizes overall production/inventory costs. The complexity of a resulting EPQ model depends on the assumptions one makes about various parameters of the inventory system. Among these features are demand types, actions for excess demand, production rates, treatment for imperfect quality items, minimal service level constraint, various cost parameters, and issuing policies when items are perishable. The classic EPQ model assumes that manufacturing facility functions perfectly during a production run. However, due to process deterioration or other factors, the generation of imperfect quality items is inevitable. These defective items can be reworked and repaired with additional repairing and holding costs $[4,7,10]$. For examples, printed circuit board assembly (PCBA) in PCBA manufacturing, plastic goods in the plastic injection molding process, and production process in other industries, such as chemicals, textiles, metal components, etc., sometimes employ rework as an acceptable process in terms of level of quality. A considerable amount of research has been carried out to address the imperfect quality issue of production system as well $[3,5,9,15]$.

This paper examines the optimal lot-size decision for an EPQ model with rework and service level constraint. In real world inventory control and management, due to certain internal orders of parts/materials and other operating considerations, the planned backlogging is the strategy to effectively minimize overall inventory costs. While allowing backlogging, abusive shortage in an inventory model, however, may cause an 
unacceptable service level and turn into possible loss of future sales (because of the loss of customer goodwill). Therefore, the minimal service level is always set as an operating constraint of the business while deriving the optimal lot-size decision. A noticeable amount of research has been conducted to address the service level constraint issue $[1,6,8,11]$. Other examples of them are surveyed below. Schneider [16] examined a $(Q, S)$ model, he determined the optimal value of the order quantity $Q$ and the reorder point $s$ in which the average annual costs of inventory and orders are minimal under the condition that a certain service level is reached. Ouyang and $\mathrm{Wu}$ [13] developed an algorithm to find the optimal order quantity and optimal lead time for an inventory model with a service level constraint and when the probability distribution of the lead time demand is normal. Chen and Krass [2] investigated inventory models with minimal service constraints. They showed that the minimal service level constraint (SLC) model to be qualitatively different from their shortage cost counterparts and the transformation from SLC model to a shortage cost model may not be always possible. This paper extends the work of Hayek and Salameh [7] and Chiu [4], studies the effect of service level constraint on the optimal lot-size decision of an EPQ model with rework.

\section{NOTATIONS AND ASSUMPTIONS}

In the real world manufacturing systems, due to process deterioration or various factors, a process may randomly produce $x$ percent of defective items at a rate $d$. In the studied model, all of the defective items produced are assumed to be repairable. When regular production ends, the reworking of defective items starts immediately, at a rate $P_{l}$. Hence, the production rate $d$ of imperfect quality items can be expressed as $d=P x$. The following notations are used:

$\lambda=$ demand rate, in units per unit time,

$P=$ production rate in units per unit time,

$P_{1}=$ rate of rework of defective items in units per unit time,

$x=$ the percentage of imperfect quality items produced; a random variable with a known probability density function.

$d=$ production rate of the defective items in units per unit time,

$Q=$ production lot size in the EPQ model with shortage not permitted,

$Q_{b}=$ production lot size per cycle in the EPQ model with shortage allowed and backordered,

$B$ = allowable backorder level in the EPQ model with backlogging permitted,

$H=$ the level of on-hand inventory in units, when the rework process ends,

$H_{1}=$ the maximum level of on-hand inventory in units, when the regular production process stops,

$K$ = fixed setup cost for each production run,

$c=$ production cost per item ( $\$ /$ item, inspection cost per item is included),

$h=$ holding cost per item per unit time (\$/item/unit time),

$h_{1}=$ holding cost for each imperfect quality items being reworked per unit time (\$/item/unit time),

$b=$ backordering cost per item per unit time,

$c_{R}=$ repair cost for each imperfect quality item reworked (\$/item),

$T=$ the cycle length, 
$E[T C U(Q)]=$ the expected total inventory costs per unit time in the EPQ model with shortage not permitted,

$E\left[T C U\left(Q_{b}, B\right)\right]=$ the expected total inventory costs per unit time in the EPQ model with backlogging permitted.

\section{MATHEMATICAL MODELLING AND ANALYSIS}

\subsection{Formulation of the EPQ Model with Rework and Backlogging}

In this study, the production rate of perfect quality items must always greater than or equal to the sum of the demand rate and the production rate of defective items. Therefore, we must have the following: $(P-d-\lambda) \geq 0$ or $(1-x-\lambda / P) \geq 0$. For the following derivation, we employ the solution procedures used by Hayek and Salameh [7]. Figure 1 depicts the on-hand inventory level and allowable backorder level for the EPQ model with backlogging permitted. One can obtain the cycle length $T$, production uptime $t_{l}$, on-hand inventory level $H_{1}$ and $H$, time needed to rework defective items $t_{2}$, production downtime $t_{3}$, shortage permitted time $t_{4}$, and $t_{5}$ as follows:

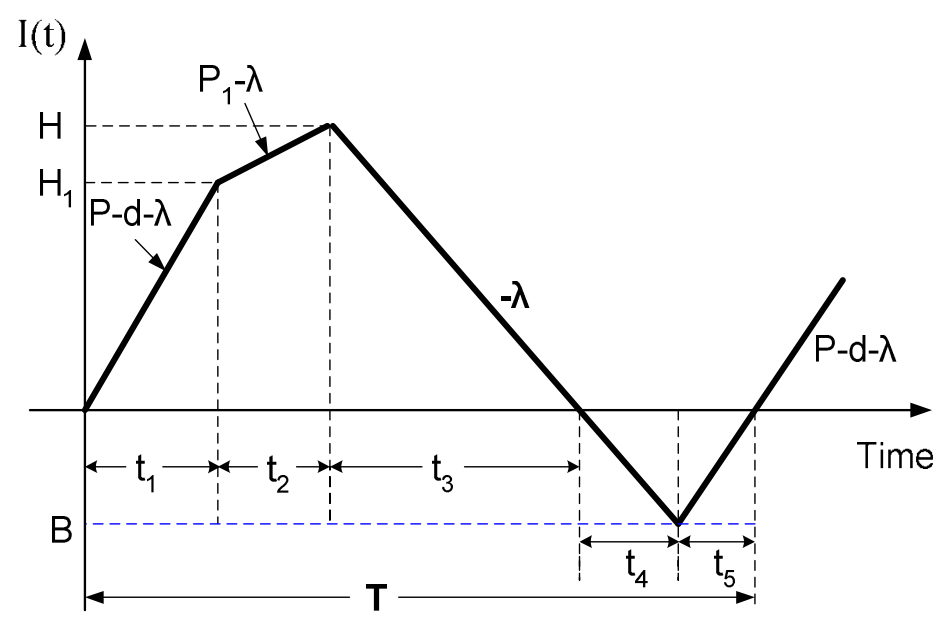

Figure 1: On-hand inventory of EPQ model with the rework of defective items and backlogging permitted [7]

$$
\begin{aligned}
t_{1} & =\frac{H_{1}}{P-d-\lambda} \\
H_{1} & =(P-d-\lambda) \frac{Q_{b}}{P}-B \\
H & =H_{1}+\left(P_{1}-\lambda\right) t_{2} \\
t_{2} & =\frac{x \cdot Q_{b}(1-\theta)}{P_{1}} \\
t_{3} & =\frac{H}{\lambda} \\
t_{4} & =\frac{B}{\lambda}
\end{aligned}
$$




$$
\begin{gathered}
t_{5}=\frac{B}{P-d-\lambda} \\
T=\sum_{i=1}^{5} t_{i}=\frac{Q_{b}(1-\theta \cdot x)}{\lambda}
\end{gathered}
$$

Hence, the expected cost $E\left[T C U\left(Q_{b}, B\right)\right]$ can be obtained as derived by [7]:

$$
\begin{aligned}
E\left[T C U\left(Q_{b}, \mathrm{~B}\right)\right]= & \lambda\left[c+c_{R} \cdot E[x]\right]+\frac{K \lambda}{Q_{b}}+\frac{h}{2}\left[\left(1-\frac{\lambda}{P}\right) \cdot Q_{b}-2 B\right] \\
& +\frac{\lambda Q_{b}}{2 P_{1}}\left(h_{1}-h\right) \cdot E\left[x^{2}\right]+\frac{B^{2}}{2 Q_{b}}(b+h) \cdot E\left(\frac{1-x}{1-x-\frac{\lambda}{P}}\right)
\end{aligned}
$$

For the proof of convexity of $E\left[T C U\left(Q_{b}, B\right)\right]$, one can utilize the Hessian matrix equation [14] as shown below. Eq. (10) is resulting positive. Hence, the expected cost function $E\left[T C U\left(Q_{b}, B\right)\right]$ is a strictly convex function for all $Q_{b}$ and $B$ are different from zero. The optimal production lot size $Q_{b}{ }^{*}$ and optimal backorder level $B^{*}$ can be derived by differentiating $E\left[T C U\left(Q_{b}, B\right)\right]$ with respect to $Q_{b}$ and to $B$, and then solving the linear system. Results are shown in Eqs. (11-12) as that were derived by [7]:

$$
\begin{gathered}
{\left[\begin{array}{ll}
Q_{b} & B
\end{array}\right] \cdot\left[\begin{array}{cc}
\frac{\partial^{2} E\left[T C U\left(Q_{b}, \mathrm{~B}\right)\right]}{\partial Q_{b}^{2}} & \left.\frac{\partial^{2} E\left[T C U\left(Q_{b}, \mathrm{~B}\right)\right]}{\partial Q_{b} \partial B}\right] \cdot\left[\begin{array}{c}
Q_{b} \\
B
\end{array}\right]=\frac{2 K \lambda}{Q_{b}}>0 \\
\frac{\partial^{2} E\left[T C U\left(Q_{b}, \mathrm{~B}\right)\right]}{\partial B \partial Q_{b}} & \left.\frac{\partial^{2} E\left[T C U\left(Q_{b}, \mathrm{~B}\right)\right]}{\partial B^{2}}\right]
\end{array}\right.} \\
Q_{b}^{*}=\sqrt{\frac{2 K \lambda}{h\left(1-\frac{\lambda}{p}\right)+\frac{\lambda \cdot\left(h_{1}-h\right)}{p_{1}} E\left[x^{2}\right]-\frac{h^{2}}{(b+h) \cdot E\left(\frac{1-x}{1-x-\frac{\lambda}{P}}\right)}}} \\
B^{*}=\left(\frac{h}{b+h}\right) \frac{1}{E\left(\frac{1-x}{1-x-\frac{\lambda}{P}}\right)} Q_{b}^{*}
\end{gathered}
$$

\subsection{Formulation of the EPQ Model with Rework and Shortage Not Permitted}

For the finite production model with random defective rate and shortage not permitted, the cycle length $T=t_{1}+t_{2}+t_{3}$ (refer to Figure 2). The expected annual cost $E[T C U(Q)]$ can be obtained as presented in Eq. (13). Differentiating $E[T C U(Q)]$ with respect to $Q$, we find that $E[T C U(Q)]$ is convex and one can derive $Q^{*}[5]$, as shown in Eq. (14).

$$
\begin{gathered}
E[T C U(Q)]=\lambda\left[c+c_{R} \cdot E[x]\right]+\frac{K \lambda}{Q}+\frac{h \cdot Q}{2}\left(1-\frac{\lambda}{P}\right)+\frac{\lambda Q}{2 P_{1}}\left(h_{1}-h\right) \cdot E\left[x^{2}\right] \\
Q^{*}=\sqrt{\frac{2 K \lambda}{h\left(1-\frac{\lambda}{p}\right)+\frac{\lambda \cdot\left(h_{1}-h\right)}{p_{1}} E\left[x^{2}\right]}}
\end{gathered}
$$




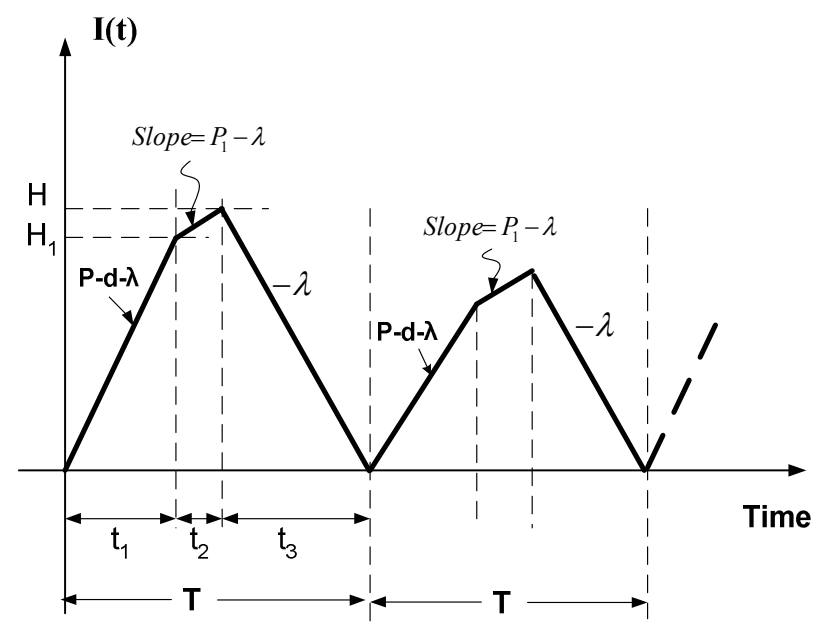

Figure 2: On-hand inventory of the finite production model with the reworking of defective items [5]

\subsection{The Effects of Backlogging and Shortage Level Constraint on the Model}

Property 1. The expected annual cost per unit time for the imperfect EPQ model with backlogging not permitted is always greater than or equal to that of the EPQ model with backlogging allowed. That is $E[T C U(Q)] \geq E\left[T C U\left(Q_{b}, B\right)\right]$, for any given $Q=Q_{b}$.

Proof. Assumes that for any given $Q=Q_{b}$, employing Eqs. (9) and (13), one obtains:

$$
E[T C U(Q)]-E[T C U(Q, B)]=h \cdot B-\frac{B^{2}}{2 Q}(b+h) E\left(\frac{1-x}{1-x-\frac{\lambda}{P}}\right)
$$

Substituting $B$, we have:

$$
E[T C U(Q)]-E[T C U(Q, B)]=\frac{h^{2}}{2(b+h)}-\frac{1}{E\left(\frac{1-x}{1-x-\frac{\lambda}{P}}\right)} Q \geq 0
$$

Since cost related parameters $h$ are $b$ are non-negative numbers, the random defective rate $x$ is within the interval of $[0,1],(1-x-\lambda / P) \geq 0$, and the production lot-size $\mathrm{Q} \geq 0$, hence Eq. (15) $\geq 0$.

Property 1 confirms that it is better off to permit backlogging for the imperfect EPQ model with rework. While allowing backlogging, abusive shortage in an inventory model, however, may cause an unacceptable service level and turn into possible loss of future sales. Hence, the minimal service level per cycle is always set as an operating constraint for the business. Suppose that we set $\alpha$ to be the maximum proportion of shortage permitted time per cycle (that is the service level $=(1-\alpha) \%$ ), then:

$$
\begin{gathered}
\alpha=\frac{t_{4}+t_{5}}{T} \\
\therefore \frac{\alpha}{1-\alpha}=\frac{t_{4}+t_{5}}{t_{1}+t_{2}+t_{3}}
\end{gathered}
$$


Substituting $t_{1}, t_{2}, t_{3}, t_{4}$, and $t_{5}$ in Eq. (17), one obtains:

$$
\therefore \frac{\alpha}{1-\alpha}=\frac{B}{\left(1-x-\frac{\lambda}{P}\right)\left(\frac{1}{1-x}\right) Q_{b}-B}
$$

Substituting $B$ in Eq. (18), one has the following:

$$
\begin{aligned}
\frac{1}{\alpha} & =\left(\frac{b+h}{h}\right)\left(\frac{1-x-\frac{\lambda}{P}}{1-x}\right) E\left(\frac{1-x}{1-x-\frac{\lambda}{P}}\right) \\
\therefore b & =h \cdot\left\{\frac{1}{\alpha} \cdot\left[\frac{1-x}{\left(1-x-\frac{\lambda}{P}\right)} \cdot E\left(\frac{1-x}{1-x-\frac{\lambda}{P}}\right)^{-1}\right]-1\right\}
\end{aligned}
$$

Assume that

$$
f(\alpha)=h \cdot\left\{\frac{1}{\alpha} \cdot\left[\frac{1-x}{\left(1-x-\frac{\lambda}{P}\right)} \cdot E\left(\frac{1-x}{1-x-\frac{\lambda}{P}}\right)^{-1}\right]-1\right\} .
$$

Eq. (21) represents the relationship between the imputed backorder cost $f(\alpha)$ and the maximum proportion of shortage permitted time $\alpha$. In other words, when the service level $(1-\alpha) \%$ of the EPQ model is set, the corresponding imputed backorder cost $f(\alpha)$ can be obtained. Hence one can utilize this information to determine whether or not the service level is achievable.

Let $b_{t}$ be the tangible backorder cost per item, if $b_{t}>f(\alpha)$ then the service level $(1-\alpha) \%$ is achievable. Otherwise, we need to increase the tangible backorder cost to $f(\alpha)$ and then use it to derive the new optimal operating policy (in terms of $Q_{b}{ }^{*}$ and $B^{*}$ ), so that the overall inventory costs can be minimized and the service level constraint can be attained too. Let $b_{i}$ be the adjustable intangible backorder cost (per item per unit time), then $b_{i}$ should satisfy the following condition in order to achieve $(1-\alpha) \%$ service level:

$$
b_{i} \geq[f(\alpha)-b t]
$$

Therefore, by using $b=f(\alpha)$ one can derive the new optimal production lot-size $Q_{b}{ }^{*}$ and the optimal backorder level $B^{*}$ that minimizes the expected annual inventory costs as well as achieves the minimal service level $(1-\alpha) \%$. Figure 3 depicts the relationship between $f(\alpha)$ and $\alpha$, and pinpoints the value of $f(\alpha=0.2)$ in accordance with service level $(1-\alpha) \%$ set at minimum of $80 \%$.

Suppose that the process produces no imperfect quality items, i.e. $x=0$, the same as classic EPQ model with service level constraint. From Eq. (21) we obtain $f(\alpha)$ as:

$$
f(\alpha)=h \cdot\left(\frac{1}{\alpha}-1\right) \cdot
$$

\section{NUMERICAL EXAMPLE AND DISCUSSION}

A company produces a product for several domestic clients. This item has experienced a relatively flat demand of 4,000 units per year and the production rate is 10,000 units per 
year. The percentage of defective items produced is uniformly distributed over the interval $[0,0.1]$. All defective items are reworked right after regular production ends, at a rate of 600 units per year. The service level of this item, according to the firm's policy, is set at $70 \%$ or above (that is the maximum proportion of shortage permitted time per cycle $\alpha$ is 0.3 ). The accounting department has estimated cost parameters as follows.

$K=\$ 450$ for each production run,

$c=\$ 2$ per item,

$c_{\mathrm{R}}=\$ 0.5$ for each item reworked,

$h=\$ 0.6$ per item per unit time.

$h_{1}=\$ 0.8$ per item per unit time.

$b_{t}=\$ 0.2$ per item backordered per unit time (the tangible backorder cost).

First let $b=b_{t}$, from Eqs. (9), (11), and (12), one obtains $\mathrm{E}\left[\operatorname{TCU}\left(Q_{b}{ }^{*}, B^{*}\right)\right]=\$ 8,713$, $Q_{b}{ }^{*}=5,877$, and $B^{*}=2,549$. For the EPQ model with backlogging not allowed, from Eqs. (13) and (14), we obtain $\mathrm{E}\left[T C U\left(Q^{*}\right)\right]=\$ 9,245$ and $Q^{*}=3,143$. One notices that the EPQ model with backlogging permitted has a lower overall cost than that of EPQ model without backlogging, as proved by Property 1 (see Figure 4).

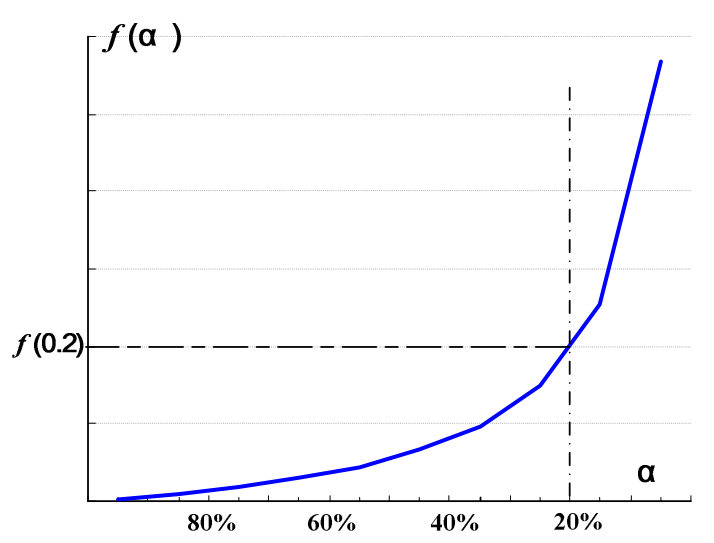

Figure 3: Variation of the maximal permitted shortage rate $\alpha$ effects on the imputed backorder $\operatorname{cost} f(\alpha)$

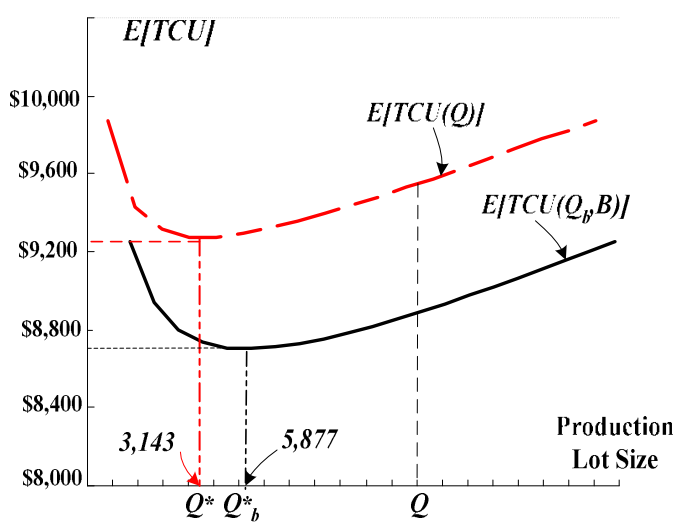

Figure 4: A comparison between the expected costs $\mathrm{E}[T C U(Q)]$ and $\mathrm{E}\left[T C U\left(Q_{b}, B\right)\right]$

\subsection{The Effect of Service Level Constraint on the EPQ Model}


In this example, suppose we ignore the $70 \%$ service level constraint for now, then from Eq. (19) the proportion of shortage time per cycle, $\alpha=0.781$. This represents a $21.9 \%$ service level only. Variation of $x$ effects on the $f(\alpha)$ is depicted in the Figure 5 and change of $\lambda / P$ effects on the $f(\alpha)$ is displayed in Figure 6.

In order to achieve the required $70 \%$ service level (i.e. $\alpha=0.3$ ), one can use the proposed Eqs. (20-21) and obtain the intangible backorder cost $b_{i} \geq\left[f(\alpha)-b_{t}\right]=1.28$. Then using a minimum $b=\left(b_{t}+b_{i}\right)=1.48$, one can re-calculate the optimal production policy $Q_{b}{ }^{*}=3,690, B^{*}=615$; and the expected costs $\mathrm{E}\left[T C U\left(Q_{b}{ }^{*}, B^{*}\right)\right]=\$ 9,076$.

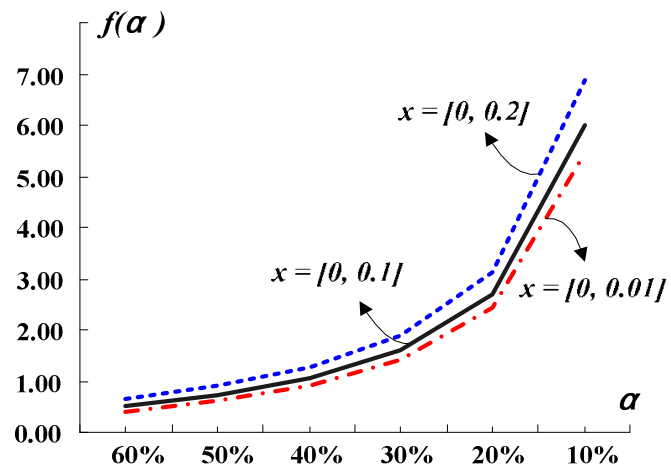

Figure 5: Variation of $x$ effects on the $\mathrm{f}(\alpha)$

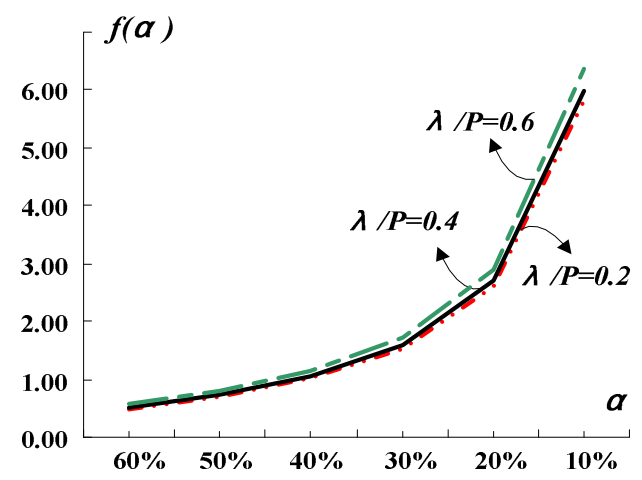

Figure 6: Change of $\lambda / P$ effects on the $f(\alpha)$

Table 1 presents the variation of $\alpha$ effects on the $f(\alpha)$, the optimal operating policy $\left(Q_{b}{ }^{*}\right.$ and $\left.B^{*}\right)$, the expected cost function $\mathrm{E}\left[T C U\left(Q_{b}{ }^{*}, B^{*}\right)\right]$, the $\mathrm{E}\left[T C U\left(Q_{b}{ }^{*}, B^{*}\right)\right]$ excluding an intangible backorder cost, and the price for raising the service level from $21.9 \%$. From Table 1, one notices that though the $\mathrm{E}\left[\operatorname{TCU}\left(Q_{b}{ }^{*}, B^{*}\right)\right]$ for $70 \%$ service level is $\$ 9,076$, if we exclude the intangible backorder cost $b_{i}$ (which merely helping us to achieve the $70 \%$ service level); then using Eq. (9), we will obtain the actual cost $\$ 8,962$. Comparing this to $\$ 8,713$, there is an increase of $\$ 249$ in cost.

In other words, \$249 is the price that we actually pay for raising the service level from $21.9 \%$ to $70 \%$ (see both Table 1 and Figure 7 for details). One also notices that as the service level $(1-\alpha) \%$ increases, both the cost function $\mathrm{E}\left[T C U\left(Q_{b}{ }^{*}, B^{*}\right)\right]$ and the actual price for raising the service level increase too.

Table 1: Variation of $\alpha$ effects on optimal operating policy, $\mathrm{E}\left[T C U\left(Q_{b}{ }^{*}, B^{*}\right)\right]$ and the $\left[T C U\left(Q_{b}{ }^{*}, B^{*}\right)\right]$ excluding the intangible backorder cost, and price for raising the service level 


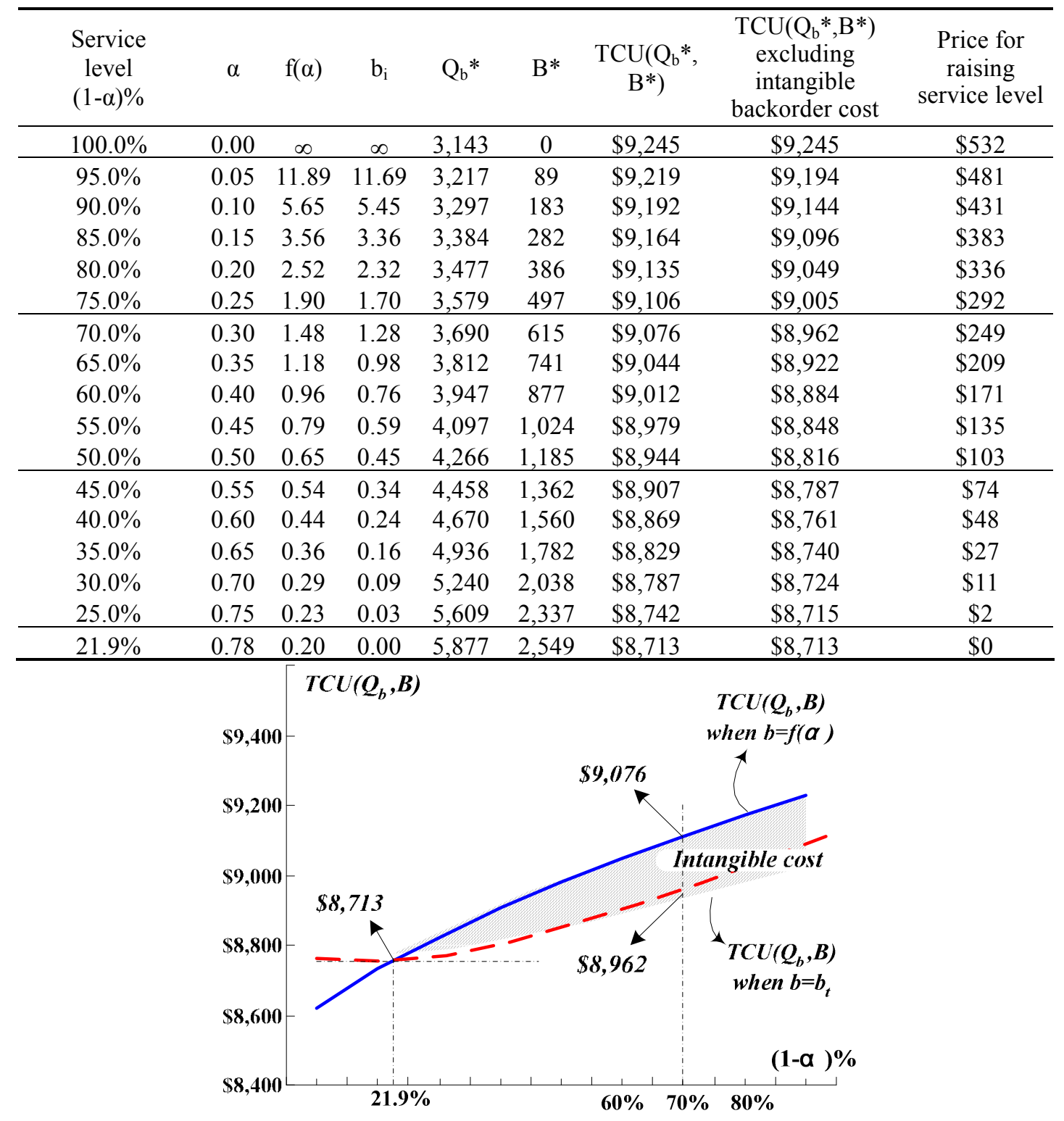

Figure 7: Variation of $\alpha$ effects on the optimal cost $\mathrm{E}\left[T C U\left(\mathrm{Q}_{\mathrm{b}}, B\right)\right]$ and the $\mathrm{E}\left[T C U\left(Q_{\mathrm{b}}, B\right)\right]$ excluding the intangible backorder cost

\section{CONCLUDING REMARKS}

This paper examines an EPQ model with rework and service level constraint. In most practical production settings, the generation of imperfect quality items is inevitable. These defective items, sometimes, can be reworked and repaired with additional repairing and holding costs. Also, the planned backlogging is proved to be the strategy to effectively minimize overall inventory costs. While allowing backlogging, abusive shortage in an inventory model, however, may cause an unacceptable service level and turn into possible loss of future sales. Therefore, the maximal shortage level constraint is always set as an operating policy to attain the minimal service level. In this paper, we first prove that the expected overall inventory costs for the imperfect EPQ model with backlogging not permitted is greater than or equal to that of the imperfect EPQ model with backlogging. Secondly, the relationship between imputed backorder cost and maximal shortage level is 
derived for decision-making on whether the required service level is achievable. Then we propose an equation for calculating the intangible backorder cost for the situation when the required service level is not attainable. By using this intangible backorder cost in the mathematical analysis, one can derive a new optimal lot-size policy that minimizes expected total costs as well as satisfies the service level constraint. Numerical example is provided to demonstrate its practical usage.

\section{REFERENCES}

1. D. Bertsimas and I.C. Paschalidis, Probabilistic service level guarantees in make-to -stock manufacturing systems. Operations Research. 49, 1, 119-136, 2001.

2. F.Y. Chen and D. Krass, Inventory models with minimal service level constraints. European Journal of Operational Research. 134, 1, 120-140, 2001.

3. T.C.E. Cheng, An economic order quantity model with demand-dependent unit production cost and imperfect production processes. IIE Tran. 23, 23-28, 1991.

4. Y.P. Chiu, Determining the optimal lot size for the finite production model with random defective rate, the rework process, and backlogging. Engineering Optimization. 35, 427-437, 2003.

5. Y.P. Chiu and S.W. Chiu, The finite production model with the reworking of defective items. Int. J. Ind. Eng. - Theory, Appl. \& Prac. 12, 1, 15-20, 2005.

6. A.G. de Kok, Approximations for a lost-sales production/inventory control model with service level constraints. Management Science. 31, 6, 729-737, 1985.

7. P.A. Hayek and M.K. Salameh, Production lot sizing with the reworking of imperfect quality items produced. Prod. Plan. Cont. 12, 584-590, 2001.

8. W.J. Hopp, M.L. Spearman, and R.Q. Zhang, Easily implementable inventory control policies. Operations Research, 45, 3, 327-340, 1997.

9. H.L. Lee and M. Rosenblatt, Simultaneous determination of production cycle and inspection schedules in a production system. Manag. Sci. 33, 1125-1136, 1987.

10. J.J. Liu and P. Yang, Optimal lot-sizing in an imperfect production system with homogeneous reworkable jobs. Euro. J. Oper. Res. 91, 517-527, 1996.

11. R. Metters and V. Vargas, A comparison of production scheduling policies on costs, service level, and schedule changes. Production\&Operations Management. 8, 1, 76-91, 1999.

12. S. Nahmias, Production\&Operations Analysis. McGraw-Hill Co.Inc 203-214, 2001.

13. L-Y. Ouyang and K-S. Wu, Mixture inventory model involving variable lead time with a service level constraint Computers\&Operations Research.24,9,875-882, 1997.

14. R.L. Rardin, Optimization in Operations Research, Prentice-Hall,Inc.739-741, 1998.

15. M.J. Rosenblatt and H.L. Lee, Economic production cycles with imperfect production processes. IIE Tran. 18, 48-55, 1986.

16. H. Schneider, The service level in inventory control systems. Engineering Costs and Production Economics. 4, 341-348, 1979.

17. E.A. Silver, D.F. Pyke and R. Peterson, Inventory Management and Production Planning and Scheduling. John Wiley \& Sons, Inc. 151-172, 1998. 